\title{
Escuela, del liberalismo al neoliberalismo
}

\author{
Tensiones entre el cercamiento y lo común
}

\author{
Noelia Fernández GonzÁlez* | HéCtor MonarCA**
}

Ante el interés por la noción de lo común en el debate académico de los últimos años, en este artículo pensamos en la escuela desde las nociones de lo común y de cercamiento, tal y como se han planteado recientemente dentro de la corriente marxista autonomista. Al combinar este debate con aportes postestructuralistas, enmarcamos la introducción y expansión de la escuela en el siglo XIX como un cercamiento masivo que organiza la socialización al servicio del capitalismo industrial. Sin embargo, en sus pretensiones universalizadoras y democratizadoras observamos esfuerzos por hacer un común de la escuela. Así, vemos que la escuela se entreteje en la tensión entre la lógica de cercamiento y sus posiciones sobre lo común. Finalmente, situamos las políticas neoliberales de la educación como un recercamiento que profundiza en su lógica liberal y meritocrática.

Given the interest in the notion of Commons in the academic debate of recent years, this article approaches schooling from the point of view of the commons and enclosure as they have recently been set forth within the autonomist Marxist current. Combining this debate with certain poststructuralist contributions, we demarcate the introduction and expansion of the school in the 19th century as a massive enclosure that organizes socialization in the service of industrial capitalism. However, in its universalizing and democratizing claims we observe some efforts to make the school a common space. Thus, we find that the school institution is intertwined with the tensions between the logic of enclosure and its position regarding the commons. Finally, we consider the neoliberal education policies as further enclosures that deepen on its own liberal and meritocratic logic.
Palabras clave

Escuela

Liberalismo

Neoliberalismo

Lo común

Cercamiento
Keywords

School

Liberalism

Neoliberalism

Commons

Enclosure

Recepción: 11 de junio de 2020 | Aceptación: 15 de junio de 2021

DOI: https://doi.org/10.22201/iisue.24486167e.2022.175.60012

* Profesora en el Departamento de Historia de la Educación y Educación Comparada de la Universidad Nacional de Educación a Distancia (UNED) (España). Doctora en Educación. Línea de investigación: políticas educativas. Publicaciones recientes: (2021, en coautoría con H. Monarca y Á. Méndez), "Orden social, Estado y escuela: de la producción de lo común a la producción de la diferencia”, Recerca. Revista de Pensament i Análisi, vol. 25, núm. 2. DOI: https://doi.org/10.6035/Recerca.2020.25.2.7; (2020), "Una sociología discursiva de la política educativa: rastreando las tensiones del gobierno neoliberal de la escuela pública”, Revista de Estudios Teóricos y Epistemológicos en Política Educativa, vol. 5, pp. 1-19. DOI: https://doi.org/10.5212/retepe.v.5.15039.012.CE: nfernandez@edu.uned.es

** Profesor en el Departamento de Pedagogía de la Universidad Autónoma de Madrid (UAM) (España). Doctor en Educación. Líneas de investigación: política educativa; evaluaciones externas; desarrollo profesional docente; políticas de apoyo educativo. Publicaciones recientes: (2021, en coautoría con N. Fernándezy Á. Méndez),"Social Order Regimes of Truth and Symbolic Disputes: A Framework to Analyse Educational Policies", Filosofija. Sociologija, vol. 31, núm. 1, pp. 42-50; (2020), "Ciencia, poder y regímenes de verdad en textos académicos sobre acceso a la profesión docente”, Archivos Analíticos de Políticas Educativas, vol. 29, núm. 81. DOI: https://doi.org/10.14507/epaa.29.5373. CE: hector.monarca@uam.es 


\section{INTRODUCCIÓN ${ }^{1}$}

En el año 2015, la UNESCO publicó el informe Repensar la educación, ¿hacia un bien común mundial? Con este texto se incorporaba a un debate más amplio en torno a la noción de "lo común" que, con diversas formulaciones - "los comunes", "el bien común", "los bienes comunes" - venía cobrando visibilidad dentro de la academia. Fuera de ella, la apelación a lo común en las voces de militantes y activistas sociales se ha vinculado a reclamos por una democracia de base, participativa, que atienda al principio de igualdad, para desde ahí desarrollar una gestión directa de los recursos por parte de la ciudadanía y de las comunidades, desde el acceso al agua hasta el acceso a la vivienda (Laval y Dardot, 2015). Así, por ejemplo, las iniciativas de colectivos vecinales para afrontar la grave crisis social de la COVID-19 han sido inmediatamente enmarcadas como una muestra del "cuidado de lo común” (MIRCO, 2020). Sin embargo, esta gestión directa y atenta al principio de igualdad plantea grandes desafíos en el caso de recursos de alcance global, como el medio ambiente (Harvey, 2011); e igualmente en el caso de recursos gestionados a nivel estatal, como pueden ser la escolarización o la sanidad públicas allá donde los Estados de bienestar las hayan llegado a proveer (Caffentzis y Federici, 2015; Dardot y Laval, 2019).

Específicamente en el debate académico, lo común ha sido un nodo de reflexión desde distintas tradiciones de pensamiento: el marxismo culturalista de Linebaugh (2013), discípulo de Edward P. Thompson; el autonomismo marxista y feminista de Federici (2010); el marxismo autonomista y post-operaísta de Negri (2015); la propuesta basada en Castoriadis de Laval y Dardot (2015) o el neoinstitucionalismo económico de Ostrom (Hess y
Ostrom, 2016). A estas perspectivas también podemos añadir la mirada desde la filosofía de Jean-Luc Nancy o de Roberto Esposito, quienes, con matices propios, convergen en la exploración de la ontología de lo común (Garcés, 2013; Saidel, 2019). Lo común, por lo tanto, está siendo recuperado en la reflexión teóricopolítica y en el activismo y la militancia de base, retroalimentándose lo uno con lo otro.

En este trabajo nos apoyaremos en la corriente marxista asociada a visiones autonomistas de la política y de la democracia. Este abordaje, que busca imaginar y construir alternativas políticas anticapitalistas y posneoliberales, ha recibido atención en las últimas décadas en la búsqueda de respuestas ante la nueva ronda de cercamientos que implica la globalización neoliberal (Harvey 2004) y que afecta a recursos naturales, recursos inmateriales - como la cultura o el conocimiento-, bienes y servicios público-estatales; e incluso al material genético (Laval y Dardot, 2015). Esta noción de cercamiento nos sitúa en la lectura que Marx ofrece en el capítulo XXIV del tomo I de El capital (1975) de la llamada acumulación originaria. En ese capítulo se distancia del relato que Adam Smith hacía del inicio del capitalismo como fruto del ahorro diligente de algunos frente a la holgazanería de otros, y recupera una historia de robos y violencias por la que la tierra fue privatizada en Inglaterra para pasar de la etapa precapitalista al orden capitalista. En este proceso de cercamientos el campesinado fue despojado de sus medios de subsistencia y de sus derechos sobre la tierra, lo que era necesario para su proletarización. Este movimiento de cercamientos iniciales de la tierra revela la alianza entre el capital y un Estado en ciernes que colabora en estos procesos de concentración de riqueza. Actualmente, el paradigma de los cercamientos y de lo común (Laval y Dardot, 2015) o del procomún

\footnotetext{
${ }^{1}$ Este artículo fue redactado en el marco de la elaboración del proyecto de investigación I+D+i "Profesionalización docente: discursos, políticas y prácticas. Nuevos enfoques y propuestas” (PID2020-112946GB-I00) financiado por el Ministerio de Ciencia e Innovación de España en la convocatoria 2020 del Programa estatal de generación de conocimiento y fortalecimiento científico y tecnológico del sistema de I+D+i, del Plan Estatal de Investigación Científica y Técnica y de Innovación 2017-2020.
} 
(Bollier 2016) recupera este relato de violencia para enmarcar los procesos de privatización y mercantilización del neoliberalismo.

En línea con Hardt y Negri, Žižek (2011) enumera tres aspectos de lo común que en la actualidad se ven acechados por esta lógica neoliberal: lo común de la cultura, que incluye el capital cognitivo socializado, como la educación y las infraestructuras; lo común de la naturaleza externa, que son los recursos naturales; y lo común de la naturaleza interna, la herencia biogenética de la humanidad. $\mathrm{Y}$, tras enumerarlas, destaca la amenaza clave de estos cercamientos, en la medida en que generan "nuevas formas de apartheid, nuevos muros y ciudades de miseria" (Žižek, 2011: 106). Estos muros de desigualdad hacen a la sociedad menos común, no sólo en el sentido de que la riqueza es menos común al concentrarse en ciertos sectores de población, sino también en el sentido de que se generan experiencias de vida más segmentadas y desiguales, experiencias menos comunes.

En el terreno de la educación y de la escuela que aquí nos ocupa, lo común y el paradigma de los cercamientos también han sido explorados para pensar las políticas neoliberales (De Lissovoy et al., 2015; Fernández González, 2016, 2019; Frigerio y Diker, 2008; Means et al., 2017; Ramírez, 2014; Saforcada, 2009; Slater 2014). En estos trabajos se reflexiona sobre las diversas maneras en que el neoliberalismo mercantiliza y privatiza la educación: mediante teorías del capital humano que capturan el sentido de la educación dirigiéndolo hacia la acumulación de capital (De Lissovoy et al., 2015); mediante la entrada de actores empresariales en la educación que piensan en ella como un espacio de negocio ${ }^{2}$ (Saforcada 2009); mediante la organización gerencial de la escuela pública que piensa en cada centro educativo como una empresa y que, por lo tanto, proletariza al profesorado ${ }^{3}$ y borra toda posibilidad de una organización colegiada y de participación democrática en los centros (Rodríguez, 2014); o mediante un discurso que, si bien apela a la "libertad de elección", invita a las familias a pensarse como consumidoras y a las escuelas a competir entre ellas por captar alumnado, con lo cual alimenta dinámicas de segregación entre centros escolares (Fernández González, 2019).

En nuestro entender, la recuperación de esta noción tiene que ver con que lo común nos sale al paso como una oportuna categoría de pensamiento ante el agotamiento explicativo de la dicotomía público/privado (Fernández González, 2016; Laval y Dardot, 2015). El carácter empresarial del Estado y su promoción de la racionalidad de competencia (Foucault, 2007; Laval y Dardot, 2013), su papel activo en las privatizaciones de servicios estatales (Harvey, 2004) o la expansión de colaboraciones público-privadas - especialmente frecuentes en el campo educativo (Verger et al., 2016) - revelan una creciente confusión entre el Estado y el mercado generada por el neoliberalismo. La frontera entre lo público y lo privado, que en el modelo del Estado de bienestar parecía nítida, ya no lo es, de manera que ambas categorías pierden su fuerza explicativa como organizadoras de lo social.

Ante este panorama, los trabajos marxistas que ponen su foco de atención en las dinámicas de expropiación (Harvey, 2004; Luxemburgo, 1967; el capítulo XXIV del tomo I del El capital de Marx, 1975), así como el trabajo de Polanyi (2016) nos permiten entender cómo el capital y el Estado han trabajado en alianza histórica para animar los procesos de acumulación. Polanyi (2016) explica cómo el liberalismo de la primera mitad del siglo

\footnotetext{
2 Sobre este punto, el momento en que la educación es incluida en el Acuerdo General sobre el Comercio de Servicios (AGCS o GATS, por sus siglas en inglés) constituye un punto de inflexión a nivel global, ya que naturaliza la educación como esfera de negocio (Robertson et al., 2002).

3 Marx señala, precisamente, "la escisión entre el obrero y la propiedad de sus condiciones de trabajo" (1975: 893) como parte definitoria de este proceso de cercamiento de la tierra, por lo que estas dinámicas, catalogadas como proletarización del profesorado - que lo alejan de la toma de decisiones- vendrían a replicar este mismo aspecto.
} 
XIX produce la normativa -acción estatal, por tanto- que crea los mercados "autorregulados" mediante la derogación de las hasta entonces existentes regulaciones que servían para proteger a consumidores y otros pequeños intervinientes. ${ }^{4}$ Se construye así la esfera de la economía como esfera separada de la política. A una lectura similar nos permite llegar Foucault (2007) al presentar la racionalidad del liberalismo como una cuestión de agenda que separa los espacios o asuntos que conciernen al mercado y que, por lo tanto, han de ser regidos por la racionalidad de competencia; $y$ los que conciernen al Estado y a su lógica intervencionista. En este sentido, tanto Foucault como Polanyi nos ayudan a entender el modo en que el liberalismo genera la separación entre la "economía" y la "política", el "mercado" y el "Estado", de manera que se oculta el papel clave del Estado como promotor de esa separación, así como su propia alianza con el capital.

A partir del capítulo XXIV del tomo I de El capital, dedicado a la llamada acumulación originaria (Marx, 1975), dentro del pensamiento marxista se ha decantado una corriente de pensamiento centrada en las dinámicas de expropiación del capitalismo. Nancy Fraser y Rahel Jaeggi (2019) sintetizan aspectos de esta corriente a lo largo de su conversación y hablan de las condiciones de fondo del capitalismo - la esfera de la reproducción, la naturaleza continuamente expropiada y la expropiación imperialista - que generalmente han sido planteadas como externas al primer plano económico del capitalismo, pero que son en realidad sus condiciones de posibilidad. Por lo tanto, el imperialismo, las guerras y el robo (Luxemburgo, 1967), así como la explotación de la naturaleza y de los trabajos de la reproducción social (Mies, 2019) son parte necesaria de la lógica expansiva de acumulación que mueve al capitalismo. Los trabajos de Harvey (2004) sobre "la acumulación por desposesión" continúan esta línea de trabajo. Desde este prisma, las privatizaciones de servicios estatales son la manera en que el capitalismo neoliberal mercantiliza - cerca- nuevos espacios para resolver sus crisis de acumulación.

Dedicada a construir un diálogo entre marxismo y feminismo, la corriente autonomista representada por pensadoras como Maria Mies (2019) y Silvia Federici (2010) destaca cómo el capitalismo ha generado la dicotomía producción/reproducción, y con ella ha invisibilizado las tareas de la reproducción, que han quedado en el espacio del hogar y a cargo de las mujeres. Desde este marco, se ha designado "reproducción" al conjunto de trabajos no remunerados que, sin embargo, son indispensables para la reproducción de la fuerza de trabajo que opera en la sí reconocida esfera de producción. Durante la fase de capitalismo gestionado por el Estado, organizada en torno al modelo del Estado de bienestar, la alianza capital-Estado habría asumido su responsabilidad sobre determinados aspectos de esta reproducción social (Fraser y Jaeggi, 2019), que fueron "desprivatizados, pero no mercantilizados” (Fraser, 2014: 65): estas responsabilidades salieron de la esfera del hogar a lo público-estatal bajo la forma de bienes y servicios públicos. Sin embargo, en refuerzo de la lógica de acumulación del capital, actualmente "el neoliberalismo (re)privatiza y (re)mercantiliza algunos de estos servicios, al tiempo que también mercantiliza por primera vez otros aspectos de la reproducción social" (Fraser, 2014: 65). Podríamos decir que, de alguna manera, bajo el modelo del Estado de bienestar se generó una suerte de comunes estatales que, lejos de reunir los elementos de los comunes anticapitalistas (Caffentzis y Federici, 2015), ${ }^{5}$ sí podemos entenderlos como comunes en el

\footnotetext{
${ }^{4}$ Explica que entre 1830 y 1850 se derogaron numerosos reglamentos que regulaban los mercados. Al mismo tiempo, el Estado administrativo crecía al ampliar sus funciones burocráticas.

5 Es preciso puntualizar que esto se dio principalmente en países del centro y, especialmente, en Europa. Además, el modelo de economía fordista asociado al Estado de bienestar se apoyó sobre la expropiación de recursos de los países de la periferia (Fraser, 2003). Estos aspectos nos impiden romantizar el Estado de bienestar como un pasado
} 
sentido en que los identifica Bollier (2016), ya que reúnen tres elementos definitorios: un recurso (material o inmaterial); una comunidad de sujetos que los gestiona; y un marco normativo para su regulación. Especialmente, si consideramos que, históricamente, los comunes de la tierra funcionaban para garantizar el sostenimiento material de la vida (Linebaugh, 2013), podemos pensar que estos comunes que son las políticas sociales welfaristas- han tenido esta misma función de proteger la subsistencia. Es importante destacar que esta fase del capitalismo, organizada en torno al modelo del Estado de bienestar, permite dar cuenta de una parte de la historia del siglo XX, sobre todo en Europa, Estados Unidos y, con matices en los que no podemos profundizar, también en algunos países de América Latina y de Asia.

Detallemos un poco más qué comprensión de lo común adoptamos en este trabajo. En línea con Harvey (2011), entendemos que los comunes no son algo que desaparece de una vez por todas, sino que lo común está en continua producción. Harvey piensa lo común como el conjunto de relaciones sociales y de riqueza que es siempre colectivamente generado. Si extrapolamos esta idea a la escuela, lo común sería el amplio conjunto de relaciones sociales que en ella tienen lugar. El problema, señala Harvey, es que este común "está continuamente cercado y apropiado por el capital en su forma mercantilizada y monetaria” (Harvey, 2011: 105). ${ }^{6}$ Con esta observación, este autor asemeja la noción de "cercamiento" a la de "mercantilización" y apunta ya no a una acción que tiene lugar de una vez y para siempre - como puede ser el acto de levantar una valla-, sino a una continua racionalidad de construcción de lo social, a una organización de lo social a la que se le da sentido desde una lógica mercantilizadora y por su contribución a los procesos de acumulación de capital.

A partir de estas observaciones de Harvey proponemos pensar el concepto de cercamiento en sintonía con la noción de gubernamentalidad de Foucault (1999; 2007). Así, de la misma manera que Foucault (2007) distingue entre gubernamentalidad liberal y gubernamentalidad neoliberal, proponemos distinguir una fase de cercamiento liberal en la que la escuela se organiza, desde su propio origen, de acuerdo con una gubernamentalidad liberal; y una fase de cercamiento neoliberal, donde la racionalidad de competencia impregna de manera extensiva la manera de entender la educación y de organizar la escuela pública. ${ }^{7}$ Pero, precisamente porque los comunes no son algo que desaparece de una vez por todas, veremos que la propia escuela se construye también mediante esfuerzos democratizadores que nos permiten identificar en ella dimensiones de lo común. En esta línea, de la misma manera que entendemos la idea de cercamiento como una racionalidad, apuntamos también a la necesidad de reflexionar lo común como una racionalidad anticapitalista (Caffentzis y Federici, 2015) (democrática e igualitaria, por lo tanto) de construcción de lo social.

En la siguiente sección pensaremos en la introducción de la escuela ${ }^{8}$ como un cercamiento liberal que captura de manera masiva los procesos de socialización y los organiza de acuerdo con las necesidades de la reproducción social del orden capitalista y con una

al que debemos retornar; ante ello los comunes anticapitalistas emergen como un espacio desde donde imaginar la alternativa.

6 Traducción propia.

7 Como expondremos en más detalle en la cuarta sección de este ensayo, desde la perspectiva de la gubernamentalidad neoliberal, el neoliberalismo es definido como una racionalidad de competencia que se expande hacia lo público-estatal y hacia la vida íntima de las personas (Fernández González, 2020).

8 Separándonos de otros abordajes en historia de la educación, y apoyándonos en trabajos desarrollados desde enfoques postestructuralistas (Varela y Álvarez Uría, 1991; Pineau; 2001; Querrien, 1994) rechazamos el empleo transhistórico del concepto "escuela" y, por lo tanto, con este término nos referimos exclusivamente a la escuela de masas que se configura en el marco de los procesos de construcción de los Estados-nación modernos: una escuela dirigida principalmente a la infancia de las clases obreras y pobres y que en sus orígenes es eminentemente un fenómeno urbano. 
gubernamentalidad liberal; pero, al mismo tiempo, señalaremos cómo se entretejen en ella -y en tensión con su racionalidad de cercamiento- algunas dimensiones que aspiran a hacer de la escuela un común: sus pretensiones universalistas, su extensión global y una estructuración en torno al principio de igualdad. En la sección tercera abordaremos estas maneras de entender lo común de la escuela. En la cuarta sección expondremos cómo las políticas neoliberales suponen una vuelta de tuerca sobre la lógica del cercamiento liberal, al profundizar en su racionalidad competitiva, especialmente mediante las teorías del capital humano. Con este trabajo queremos situar en perspectiva histórica las modificaciones que el neoliberalismo ha supuesto en el terreno escolar. Entendemos que para comprender cabalmente estas modificaciones es preciso subrayar la línea de continuidad que supone el cercamiento neoliberal en relación con la configuración de la escuela en el orden capitalista desde su mismo origen. Con esta intención proponemos la noción de recercamiento neoliberal.

Aunque entendemos que este proceso se ha dado en distintos Estados-nación del sistema-mundo, dado que no es posible abordar la complejidad de matices existente, en este trabajo nos hemos basado principalmente en la trayectoria histórica que ha seguido la escuela en los países europeos, en los que de manera bastante evidente podemos identificar un Estado de bienestar. En este sentido, ofrecemos una interpretación de tendencias generales que no refleja los matices de cada contexto, incluso dentro del propio escenario europeo. En cualquier caso, consideramos que esta relectura de tendencias generales ofrece un marco teórico con potencialidad para pensar de manera global las tensiones sobre las que la institución escolar se ha construido a lo largo de los últimos dos siglos.

\section{LA ESCUELA DE MASAS,}

\section{UN CERCAMIENTO MASIVO}

DE LA SOCIALIZACIÓN

"El primero que, habiendo cercado un terreno, descubrió la manera de decir: esto me pertenece, y halló gentes bastante sencillas para creerle, fue el verdadero fundador de la sociedad civil" (Rousseau, 1972: 79). Con estas palabras, a modo de alegoría, Rousseau narra con sencillez cómo se fundó la propiedad privada de la tierra. Hasta tal punto es sencillo su relato que resulta difícil apreciar la precisión de lo que cuenta. Pero, efectivamente, la propiedad privada de la tierra, tal y como hoy la entendemos, se inauguró con algo tan simple como levantar una cerca. Bien es cierto, sin embargo, que esta historia es mucho más compleja y no se comprende debidamente sin atender al concurso del Estado para dar legitimidad a esas cercas y a las luchas y disputas que desataron (Federici, 2010; Linebaugh, 2013; Sevilla, 2013). La de los cercamientos de la tierra no es, como parece en las palabras de Rousseau, una historia tan armónica y lineal.

Traslademos ahora esta alegoría de Rousseau al terreno educativo y pensemos que la educación, tal y como hoy la entendemos, quizás también nació cuando alguien dijo "esto es la educación” y los demás se lo creyeron: como dice Pineau (2001), la modernidad dijo "la educación es esto" y la escuela se ocupó de ello. De nuevo veremos la necesidad de considerar el concurso del Estado, ya que la escuela de masas es una institución clave en los procesos de formación de los Estados-nación modernos (Green, 2013; Ramírez y Ventresca, 1992); e igualmente será preciso situarla en el contexto del capitalismo industrial y de sus intereses en la formación y el disciplinamiento de la mano de obra industrial (Querrien, 1994). ${ }^{9}$ En este sentido, la expansión de la escuela a otros escenarios, como por ejemplo

\footnotetext{
${ }^{9}$ En sus inicios, la escuela de masas fue un fenómeno principalmente urbano. Si bien legislativamente, por ejemplo, en España y América Latina ya en los inicios del siglo XIX se proclama constitucionalmente que deberá haber escuelas de primeras letras en cada municipio, la garantía de su infraestructura y la asistencia regular de niños
} 
en América Latina, ha sido también descrita como parte de un proyecto de modernización importado por élites reformadoras de la Ilustración europea (Newland, 1991; Ossenbach, 1993), aunque su incorporación en esta región tenga matices que exceden los objetivos y posibilidades de desarrollo en este trabajo.

De nuevo, al igual que en la historia de los cercamientos de la tierra, la expansión de la escuela tampoco fue un proceso armónico y libre de conflictos. En sus orígenes, las posturas contrarias a la expansión escolar iban desde reaccionarios favorables al antiguo régimen y liberales que veían en la educación de los pobres un peligro (Varela y Álvarez-Uría, 1991), a anarquistas que la rechazaban por entenderla un proyecto disciplinador del orden capitalista (Tomassi, 1980). Entre sus defensores podemos distinguir tanto reformadores ilustrados que la veían como una máquina civilizadora para contener la revolución (Newland, 1991; Querrien, 1994), como sectores de la izquierda que veían en la escuela una oportunidad para extender los derechos sociales y democráticos a las clases trabajadoras (Bowles y Gintis, 1976; Puiggrós, 2016). Y, finalmente, este cercamiento de los procesos de socialización que es la escuela de masas quizás tampoco sea un cercamiento en un sentido tan metafórico ya que, a fin de cuentas, la escuela se levantó como un lugar de encierro físico y paso obligatorio para las jóvenes generaciones (Lerena, 1984).

En tanto que institución propia de la modernidad y de su tradición de pensamiento, la escuela se expande como un signo de desarrollo, progreso, racionalización y civilización (Ramírez y Ventresca, 1992), términos que también hacen resonar el espíritu de la Ilustración (Popkewitz, 2009). Centrada en este discurso, la escuela trazaría un muro para excluir todos los saberes y modos de vida que no aceptará y que presentará como ilegítimos: los saberes de los pobres, de las clases obreras (Querrien, 1994) y de los pueblos originarios en los territorios colonizados (Castro-Gómez, 2000; Puiggrós, 2016). Esto se debe a que, desde su propia inauguración, la escuela siempre tuvo entre sus intereses la formación de la mano de obra necesaria para el orden capitalista, así como la civilización de esos otros sujetos abyectos que sólo tienen cabida en la escuela en la medida en que entran a ella para abandonar esas identidades otras y avanzar hacia el modelo del ciudadano moderno (Popkewitz, 2009), un modelo que responde a la imagen del propietario burgués de las urbes europeas (Castro-Gómez, 2000).

De esta forma, desde el siglo XIX y durante el siglo XX la escuela se extenderá de manera global hasta el punto de que actualmente resulta indisociable de la educación. Podríamos decir que la escuela es parte de una cultura política mundial (Ramírez y Ventresca, 1992) que se plasma, por ejemplo, en el lenguaje de los derechos, donde se establece que el derecho a la educación será garantizado mediante la escolarización, que habrá de ser obligatoria, universal y gratuitamente provista por los Estados. Este significado de la educación, inscrito en la institución escolar, es parte del proyecto político de la modernidad, un proyecto imbricado a su vez con el capitalismo y, por lo tanto, también con el colonialismo, y que se ha universalizado a través de relaciones desiguales de poder (Castro-Gómez, 2000). La expansión de la forma jurídico-política del Estado moderno/Estado nación, propia igualmente de la modernidad, trae aparejada la escuela de masas como una de sus marcas de identidad; a fin de cuentas, los sistemas escolares han sido una herramienta clave en la construcción de ciudadanos nacionales (Green, 2013).

Profundizando en su racionalidad, la escuela de masas se constituye como una tecnología de gobierno de matriz liberal inspirada por la imagen del individuo liberal, lo que cristaliza en su gramática meritocrática. Como explica Pablo Pineau (2001), la configuración

y niñas en las zonas rurales más remotas no se harán efectivas hasta muchas décadas después (Newland, 1991). 
de la escuela, no sólo como obligación, sino especialmente como un derecho, hace de ella una tecnología de gobierno dirigida a alimentar el deseo individual del estudiante por esforzarse para mejorar su posición social: la promesa de movilidad social basada en la proclamada igualdad de oportunidades, hace que la educación se comprenda como "una carrera abierta al talento” (Pineau, 2001: 43), y de esa manera subjetiva al alumnado en el modelo del individuo liberal propietario de sí.

A partir de este modelo de individuo se decanta una visión atomista de la sociedad como suma agregada de individuos (Barcellona, 1996) que suscriben un contrato social con los demás. Es aquí donde Roberto Esposito (2009) identifica el paradigma inmunitario como parte nuclear de la modernidad: a partir de esta ficción contractual el objetivo no es el de construir la comunidad, sino el de garantizar la inmunidad individual; garantizar para cada uno su espacio de no intromisión. Marina Garcés (2013) habla de una privatización de la existencia que está en el corazón mismo de la modernidad, ya que la única manera en que esta tradición liberal puede consolidarse es obviando la naturaleza dependiente del ser humano y la naturaleza común de la vida humana. Esta figura de sujeto, así como las nociones de libertad negativa y el paradigma de la inmunidad se articulan en las teorías contractualistas liberales de Hobbes, Locke y Rousseau sobre las que se apoyan los cimientos legitimadores del Estado moderno (Garcés, 2013).

Volviendo a la escuela, la gramática meritocrática replica este paradigma inmunitario: el estudiante es pensado e invitado a pensarse a través de una trayectoria de esfuerzo individual y de méritos que serán individualmente recompensados al ser reconocidos como propiedades de cada uno de los individuos. Aquí la escuela, al proclamarse neutral, se presenta como una institución ciega a los saberes que el alumnado trae consigo de sus contextos más inmediatos de socialización, y éste es el significado específico de la "igualdad de oportunidades". La respuesta del liberalismo contra el orden social del antiguo régimen es la proclamada igualdad de oportunidades. Pero, como pondrán de relieve los trabajos sociológicos de los setenta, dicha igualdad - así como la neutralidad asociada a ella- lejos de ser tal ha servido para ocultar el modo en que, en tanto que institución propia del orden capitalista, termina valorando los saberes de las clases dominantes de este orden, es decir, los saberes de las clases burguesas (Bourdieu y Passeron, 1967). Estas teorías de la reproducción de los sesenta y setenta insisten en la no neutralidad de la organización meritocrática de la escuela, algo que, desde otros marcos, y quizás con menos sofisticación investigadora, ya habían señalado pedagogos y pedagogas marxistas y anarquistas desde el momento mismo en que comenzó a extenderse la escuela (Snyders, 1978).

\section{LO COMÚN DE LA ESCUELA:}

\section{UNIVERSALISMO Y ESCUELA PÚBLICA}

“Repitámoslo: lo que llamamos 'público' es la riqueza que hemos producido nosotros y tenemos que reapropiarnos de ella". Con este conciso mensaje, Caffentzis y Federici (2015: 68) apuntan a la necesidad de conciliar las luchas por la defensa de lo público con la construcción de lo común. Desde este prisma podemos pensar a la escuela pública (estatal) como un común. Tal y como hemos expuesto en la sección anterior, entendemos que la escuela constituye un cercamiento liberal de los procesos de socialización, y hemos identificado su lógica meritocrática como parte nuclear de este cercamiento. Sin embargo, también hemos señalado en la introducción que la noción de cercamiento no designa una acción que tiene lugar de una vez y para siempre, sino que apunta a una racionalidad mercantilizadora de construcción de lo social (Harvey, 2011). En este sentido, queremos destacar que la escuela ha sido históricamente un lugar de disputa entre ambas racionalidades - la de cercamiento y la de lo común-y, 
por lo tanto, en ella podemos identificar también diversas hebras de lo común que entran en tensión, justamente, con los proyectos políticos que quieren reforzar su racionalidad mercantilizadora.

En primer lugar, podemos decir que la escuela es común, entendiendo "común" como sinónimo de "universal", ya que ella misma se proclama como universal (Ramírez y Ventresca, 1992). Como resultado de esta universalidad, Diker (2008: 149) señala que la escuela es un común como efecto: "aquello que el conjunto de la población tiene en común”. En tanto que derecho ciudadano, la escuela es un derecho de todos y de todas: es "el elemento común que toda población, por derecho y por obligación, debe compartir" (Diker, 2008: 160). En este plano la escuela, como lugar de derechos y de igualdad arranca en la proclamación liberal de igualdad de todos los ciudadanos y en contra del antiguo régimen.

A este respecto, desdela teoría postmarxista del discurso (Buenfil Burgos, 2008; Laclau y Mouffe, 2001) se ha insistido en la idea de que todo universal no es otra cosa que un particular que, fruto de relaciones de poder, ha conseguido universalizarse y volverse hegemónico. En palabras de Žižek (1998: 139): "el Universal adquiere existencia concreta cuando algún contenido particular comienza a funcionar como su sustituto" y, continúa, "el hecho de que el vínculo entre el Universal y el contenido particular que funciona como su sustituto sea contingente significa precisamente que es el resultado de una batalla política por la hegemonía ideológica”. A consecuencia de ello, todo universal implica siempre un reverso de exclusiones (Arditi, 2011). De manera específica, el liberalismo, que arranca en la noción de individuo abstracto y universal, excluye a las otras formas de vida y de sujeto por considerarlas particulares. Esa figura universal sería para la escuela moderna lo que en común tienen todos los seres humanos. Es una concepción de universalidad basada en la razón, en el consenso y el argumento, que excluye, por lo tanto, el conflicto y las pasiones (Mouffe, 2016), así como todas las otras cosmovisiones de la vida (Lander, 2000).

Si la escuela se ha vuelto un cercamiento masivo de la reproducción social simbólica, es a causa de su confianza en un residuo común, en un sustrato de igualdad universal que todos compartimos. En esta línea, "universalidad", pero también "derecho", "educación” e "igualdad" se vuelven el terreno de una tensión entre lo universal-igualitario que la modernidad presume que todos/as compartimos y una manera eurocéntrica de llenar de contenido ese universal-igualitario. Diker (2008) insiste precisamente en esta tensión que atraviesa la escuela: en la definición que la escuela haga de sus saberes o formas de vida comunes se verá siempre implicada la tarea de excluir a los que no se consideren comunes. Dentro de este mismo marco, los esfuerzos actuales por hacer de la escuela un lugar más democrático e inclusivo que considere otros modos de vida y ofrezca otros relatos de la historia, por ejemplo, desde la pedagogía decolonial (Walsh, 2013), reflejan la intención de reforzar la escuela como un común.

En segundo lugar, queremos rescatar esta posición sobre lo común en el marco del conflicto al que históricamente ha estado y sigue estando sujeta la escuela. Desde su misma introducción, distintos proyectos políticos han pugnado por organizar la socialización masiva de acuerdo con sus imágenes del mundo. Sintetizando en extremo, y en línea con Manuel de Puelles Benítez (2003), identificamos dos grandes polos de este conflicto: en un polo, el proyecto político de derechas, anclado en el liberalismo y el conservadurismo, centrado en "una vertiente privada, que pone el acento en la libertad de enseñar y de aprender, y por tanto en la libertad de creación y en la libertad de elección de centros docentes" (Puelles, 2003: 59); en el otro polo, el proyecto político de izquierdas, de raíces socialistas, cuyo centro de gravedad es el principio de igualdad, y del cual se deriva su especial atención a la garantía 
del derecho a la educación mediante la escuela pública "que trata de facilitar este derecho prestacional a todos los ciudadanos" (Puelles, 2003: 59). En esta segunda posición política identificamos una manera de proyectar la escuela como una experiencia común basada en la igualdad: como un común al que todos y todas tienen derecho de acceso en condiciones de igualdad, ya que a todos y todas pertenece en la medida en que es un espacio colectivamente construido y habitado.

En esta misma línea, por ejemplo, De Lissovoy et al. (2015) rastrean esta fuerza de lo común en la historia de la escuela estadounidense y en la disputa de la primera mitad del siglo $\mathrm{XX}$ entre reforma corporativa - promovida por el capital monopólico de magnates como J. P. Morgan y John D. Rockefeller- y el progresismo liberal -con representantes como el filósofo y pedagogo John Dewey-. Mientras los primeros veían el valor de la escuela pública en términos empresariales, por su utilidad y eficiencia para el control social y para formar la mano de obra que veían necesaria; los segundos la valoraban por su capacidad de producir una socialización y, por lo tanto, también una sociedad democrática y común. Tras la Segunda Guerra Mundial se abrió en Estados Unidos - también en Europa, o al menos en los países del centro económico europeo- un consenso keynesiano dentro del cual la escuela pública vio ampliamente incrementada su financiación y expandió los años de escolaridad obligatoria. ${ }^{10}$ A esto se añadió la influencia del discurso de los derechos civiles, que provocó una expansión democrática de la escuela durante esta era dorada del capitalismo estadounidense. En el caso de América Latina podemos rastrear este discurso educativo centrado en la equidad en la tradición de la educación popular y en sus intersecciones y tensiones con la escuela pública y el discurso civilizador de la instrucción pública (Puiggrós, 2016; Zysman, 2013).
No obstante, como los mismos autores recuerdan a propósito del ejemplo de Estados Unidos (De Lissovoy et al., 2015), es preciso no romantizar este momento de la historia ya que, ni el Estado de bienestar, ni la escuela asociada al mismo, constituyen una transformación igualitaria de la sociedad, sino más bien una mitigación de las desigualdades del orden social capitalista. Sea como fuere, sí cabe afirmar que durante esta etapa cobran protagonismo como organizadores de la escuela los discursos basados en el principio de igualdad, que vendrán a ser cuestionados y desplazados por el neoliberalismo, y entrarán en lo que denominaremos en la siguiente sección como un proceso de recercamiento de la escuela.

\section{EL CERCAMIENTO NEOLIBERAL \\ DE LA ESCUELA PÚBLICA}

En esta sección describiremos el modo en que el neoliberalismo reorganiza la escuela a través de un nuevo cercamiento que, sin embargo, no es novedoso en todos sus aspectos, sino que profundiza y expande algunos elementos inherentes a la escuela en tanto que institución propiamente liberal. Por ello, lo identificamos como un recercamiento. Insistiremos en las diferencias entre la gubernamentalidad liberal y neoliberal (Foucault, 2007) al señalar cómo la racionalidad neoliberal se corresponde con una nueva fase del capitalismo (Fraser y Jaeggi, 2019) y un nuevo modelo de Estado (un modelo de Estado competitivo especialmente orientado hacia la competencia internacional, Jessop, 2009); y describiremos algunos rasgos fundamentales de este recercamiento de escuela a partir de su racionalidad neoliberal.

Desde la teoría crítica y el marxismo heterodoxo, Nancy Fraser y Rahel Jaeggi (2019) sitúan el neoliberalismo dentro de la historia del capitalismo y distinguen cuatro fases: el capitalismo mercantil, el capitalismo liberal de la etapa industrial, el capitalismo

${ }^{10}$ En las últimas décadas este fenómeno de expansión de la escolaridad obligatoria se ha visto reflejado en cada vez más países. 
gestionado por el Estado de la etapa fordista -que se corresponde con el modelo de Estado de bienestar - y, finalmente, la actual fase de capitalismo neoliberal. Como señalamos en la introducción, la característica central del capitalismo gestionado por el Estado es que la alianza capital-Estado se hizo cargo, mediante servicios sociales y bienes públicos como la sanidad y la educación públicas, de determinados aspectos de la reproducción necesarios para el sostenimiento de la vida. En la fase de neoliberalismo, abandonarán tal responsabilidad.

El sistema capitalista ha funcionado históricamente mercantilizando cada vez más esferas de la vida (Wallerstein, 1988) y en la fase neoliberal, el capital y el Estado se topan con una suerte de "comunes estatales" generados por las políticas sociales del Estado de bienestar y susceptibles de ser cercados, es decir, privatizados y puestos al servicio de la acumulación del capital antes que para garantizar la reproducción social. En este sentido, las dinámicas de lo que Ball y Youdell (2007) denominan "privatización exógena de la educación”, por las que agentes privados con fines de negocio entran en la provisión de servicios educativos antes reservados para el Estado, expresan de manera clara cómo trabaja este cercamiento. Si seguimos la perspectiva de gubernamentalidad podremos identificar otras aristas de este recercamiento neoliberal de la escuela. ${ }^{11}$

Antes de avanzar conviene ofrecer una exposición más precisa sobre la noción de gubernamentalidad. Con este concepto, Foucault (1999) designa un modo de gobierno que se vale de los saberes de la política económica del siglo XVIII y que, en coherencia, piensa en el sujeto como un homo economicus. Mediante estos saberes económicos se pretende guiar la conducta de los sujetos, no por coacción, sino al orientar sus deseos y expectativas en clave económica para generar en ellos determinados comportamientos productivos funcionales a los procesos de acumulación. En su curso titulado El nacimiento de la biopolítica (2007), impartido en 1978, Foucault rastrea las novedades del modo de gobierno neoliberal y clarifica la diferencia entre la gubernamentalidad liberal introducida en el siglo XVIII y la gubernamentalidad neoliberal que se inaugura y extiende en el siglo Xx. Mientras la gubernamentalidad liberal separa, como una cuestión de agenda, las áreas en las que el gobierno debe intervenir y en las que no debe hacerlo - puesto que deben estar regidas por las leyes "naturales" del laissez faire (principio de competencia y ley de la oferta y de la demanda) - la gubernamentalidad neoliberal rompe esta separación y expande esos principios del laissez faire al resto de esferas de la vida, tanto hacia lo público estatal (que en la gubernamentalidad liberal constituye espacio de intervención de gobierno) como al espacio de la vida cotidiana y de la intimidad.

Por lo tanto, entendemos que el neoliberalismo es a la vez una ruptura y una continuidad en dos sentidos: en un primer sentido, es una ruptura con la fase de capitalismo gestionado por el Estado, pero al mismo tiempo una continuidad con el orden capitalista y su lógica expropiadora (Fraser y Jaeggi, 2019); en un segundo sentido, y desde una perspectiva foucaultiana que pone su foco en el modo de gobierno (Foucault 2007), es una ruptura con la gubernamentalidad liberal anterior, pero a la vez una continuación y expansión de uno de los aspectos clave del liberalismo clásico: la racionalidad de competencia, que se extiende tanto hacia la esfera público-estatal, como a la esfera de la vida íntima de los sujetos.

11 En el capítulo tercero de Fernández González (2019) hacemos una exposición más sistemática sobre los rostros de este cercamiento neoliberal de la escuela. En ese trabajo, así como en Fernández González (2016), nos detenemos también en observar cómo la introducción de la racionalidad de competencia en la esfera público-estatal, animada por la nueva gestión pública, afecta especialmente a la escuela, en tanto que genera un gobierno postburocrático que organiza a las escuelas gerencialmente y que sitúa a las familias en la posición de consumidoras, especialmente mediante políticas de elección escolar. 
En este orden de cosas, Castro-Gómez insiste en que la expansión de esta racionalidad de competencia hacia la vida íntima de las personas constituye la gran novedad de la gubernamentalidad neoliberal: se trata de un gobierno de la intimidad que alcanza a las decisiones diarias de los sujetos en sus hábitos de alimentación, de cuidado corporal, en su vida sexual... al calcular estratégicamente todas sus decisiones y al pensarse a sí mismos/as desde las teorías del capital humano (Castro-Gómez, 2015). Este gobierno de lo íntimo alcanza con especial intensidad la conducta de los sujetos en las esferas de la educación y del trabajo (Martín y Del Percio, 2020).

Pensemos ahora el cercamiento neoliberal de la educación y de la escuela desde la perspectiva de gubernamentalidad. Las teorías neoliberales del capital humano, pensadas tanto a nivel individual - donde cada sujeto es invitado a verse como empresario de sí (Brown 2016) y, por lo tanto, sus procesos educativos como procesos de autocapitalización (Rizvi y Lingard, 2013) - como a nivel estatal - los Estados ven la educación como lugar desde el cual afrontar competitivamente la así llamada "economía del conocimiento" (Fernández González y Monarca, 2018)—, nos colocan ante una manera más extensiva y difusa en la que opera este cercamiento neoliberal. En ambos niveles el sentido de la escuela es capturado por la alianza Estado-capital para ponerla al servicio de los procesos de acumulación. Un ejemplo de ello es la manera en que el "contenido de la escuela", es decir, su currículo, es modificado para priorizar saberes flexibles, como el emprendimiento y la capacidad de adaptación, que se presentan como requisitos para competir en el contexto actual de economía global (Grinberg, 2014).

Esta forma de pensar la educación no es absolutamente nueva ya que, como señalábamos en la sección segunda, la escuela de masas, desde su origen, sirvió de modo crucial a la reproducción social del orden social capitalista (Querrien, 1994; Ramírez y Ventresca,
1992; Varela y Álvarez Uría, 1991) y su gramática meritocrática siempre ha invitado al alumnado a pensar en la escuela desde una perspectiva de movilidad social y, por lo tanto, a la luz de sus expectativas laborales (Pineau, 2001). Pero, a la vez, resulta novedosa en la manera en que consigue diluir los discursos que anclaban la escuela a la idea de lo común - la escuela como espacio de igualdad universal y como una socialización compartida, tal y como veíamos en la sección anterior-. En esta disolución de los discursos basados en la igualdad identificamos un cercamiento en un plano imaginario y simbólico (De Lissovoy et al., 2015), ya que la educación es pensada exclusivamente en términos económicos: sólo es educativo y tiene lugar en la escuela aquello que permite competir en este contexto. Limita así - o podemos decir, cerca-, las maneras de pensar la educación como un proceso que se dirige hacia otros fines, como la emancipación o la equidad, y desde otros principios que no sean la competencia.

Como señalábamos en la segunda sección de este artículo, la escuela de masas ya se inauguró como un cercamiento masivo que organizó la socialización de acuerdo con una gramática meritocrática. En ese marco, el estudiante era pensado como un sujeto propietario de sí -figura propia del individualismo liberal (Barcellona, 1996) - , dueño de sus talentos y sus méritos. Ahora, el neoliberalismo y sus teorías del capital humano no plantean una novedad total, sino más bien una profundización en este modelo de sujeto: el estudiante pasa de ser pensado como propietario de sí a ser pensado como un empresario de sí (Brown, 2016); y la educación ya no es sólo un ascensor social, sino una continua inversión que en algún momento quizás sea capitalizable (todo dependerá de cómo este estudiante empresario consiga capitalizarlo). Desde este prisma, entendemos el cercamiento neoliberal de la escuela como un recercamiento, ya que es una vuelta de tuerca que continúa y profundiza una racionalidad de competencia 
que ya se plasmaba en la gramática meritocrática de la escuela.

Ante este recercamiento, ¿dónde quedan esos discursos de las izquierdas que en la sección anterior asociábamos a lo común de la escuela? Igual que al inicio señalábamos que lo común ha sido recuperado para pensar alternativas posneoliberales, académicos y académicas del campo educativo reflexionan sobre lo común de la educación desde estas inquietudes (De Lissovoy et al., 2015; Diker, 2008; Saforcada, 2009). En el terreno de la militancia y del activismo podemos igualmente identificar numerosas muestras de resistencia y rechazo colectivos a este cercamiento neoliberal de la educación en distintos lugares del mundo, como Chile (Rowe, 2017; Hernández, 2017), Estados Unidos (Apple, 2012; Rowe, 2017) o el Estado Español (Martínez-Rodríguez, 2018). Estas acciones de rechazo adoptan como consigna, en su mayoría, la defensa de la educación pública, y suelen reclamar una visión de la educación más apegada al principio de igualdad y que no se pliegue a los objetivos de acumulación de capital. Fernández González (2019) muestra cómo, para el caso español, las plataformas colectivas en defensa de la educación pública replican un discurso que recuerda fuertemente al de las fuerzas políticas socialdemócratas de los ochenta y su atención al principio de igualdad universal. Martínez-Rodríguez (2018), por su parte, analiza las conexiones entre estas plataformas y la pedagogía crítica, que plantea la educación como un proceso de emancipación de las clases oprimidas.

\section{Conclusiones}

En este texto hemos reflexionado sobre la escuela de masas como una institución que cerca de manera masiva los procesos de socialización para organizarlos al servicio del orden social del capitalismo industrial; sin embargo, en tanto que este cercamiento se postula universal, identificamos también en la escuela posiciones que aspiran a construir esta institución como un común. Así, cabe pensar que la escuela es común en tanto que se postula como universal y en tanto que experiencia comúnmente compartida por los ciudadanos y ciudadanas; no obstante, este universalismo, de carácter eurocéntrico y propio de la modernidad, excluye otros saberes y modos de vida y en ese sentido ubicamos a la escuela de masas como un lugar de tensión entre su lógica de cercamiento y lo común. En esta tensión situamos como dos polos de disputa los proyectos políticos de izquierdas y de derechas y su histórica lucha por hacer valer sus imágenes de escuela: los primeros reforzando en ella su lógica igualitaria, propia de lo común; y los segundos, reforzando su utilidad para los procesos de acumulación. Dentro de este marco, hemos presentado el neoliberalismo como un recercamiento de la educación y de la escuela que refuerza su sentido mercantil al pensar en ellas desde las teorías del capital humano. Así, el neoliberalismo no constituiría una novedad absoluta, sino un reforzamiento y profundización al subjetivar al alumnado ya no como propietario de sí, sino como un empresario de sí.

Dentro de este marco, nos gustaría dejar abierta la siguiente pregunta: ¿cómo podemos pensar la escuela desde las reflexiones sobre los comunes anticapitalistas? La respuesta se torna particularmente difícil a la luz de la gramática meritocrática definitoria de esta institución. A esta dificultad se añade que, siendo la escuela parte del aparato burocrático estatal, plantea grandes desafíos imaginar su autogobierno con base en ideas autonomistas de la democracia sin caer en una fragmentación que la convierta en una multiplicidad de centros escolares que compiten unos con otros (Dardot y Laval, 2019). No obstante, como ya hemos avanzado en otros textos, creemos que un programa de investigación que ahonde en esta pregunta deberá considerar las tensiones entre lo común y la definición de la comunidad que organiza ese común (Fernández González, 2016); o, visto desde otro ángulo, 
deberá considerar que lo común, entendido como universal, implica reverso de exclusiones (Arditi, 2011). Asumimos, por lo tanto, que toda definición de lo común siempre va a comprometer exclusiones, pero no por ello declinamos la tarea de pensar la escuela desde los comunes anticapitalistas. Por el contrario, creemos que lo común debe funcionar como un horizonte provisorio, desde donde la escuela se haga cargo de sus propias exclusiones $y$, por lo tanto, asuma la naturaleza conflictiva de la política democrática entendida como la actividad por la que los/as excluidos/as reclaman su parte. Aquí, creemos que perspectivas de la democracia centradas en el conflicto, como la de Jacques Rancière (2012) y la de Chantal Mouffe (2016) constituyen puntos de arranque idóneos para empezar a imaginar esta escuela común y anticapitalista.

\section{REFERENCIAS}

Apple, Michael (2012), Can Education Change Society?, Nueva York, Routledge.

Arditi, Benjamín (2011), La política en los bordes del liberalismo, Barcelona, Gedisa.

BALL, Stephen. J. y Deborah Youdell (2007), "Privatización encubierta en la educación pública”, Informe preliminar para el $V$ Congreso Mundial de la Internacional de la Educación, Londres, Universidad de Londres-Instituto de Educación.

Barcellona, Pietro (1996), El individualismo propietario, Madrid, Trotta.

Bollier, David (2016), Pensar desde los comunes. Una breve introducción, Buenos Aires, Traficantes de sueños.

Bourdieu, Pierre y Jean Claude Passeron (1967), Los estudiantes y la cultura, Barcelona, Labor.

Bowles, Samuel y Herbert Gintis (1976), Schooling in Capitalist America, Londres, Routledge \& Kegan Paul.

Brown, Wendy (2016), El pueblo sin atributos. La secreta revolución del neoliberalismo, Barcelona, Malpaso.

Buenfil Burgos, Rosa Nidia (2008), "Universalismo y particularismo en la globalización”, Propuesta Educativa, vol. 30, núm. 2, pp. 9-22.

Caffentzis, George y Silvia Federici (2015), "Comunes contra y más allá del capitalismo”, $E l$ Apantle. Revista de Estudios Comunitarios, núm. 1, pp. 53-71.

Castro-Gómez, Santiago (2000), “Ciencias sociales, violencia epistémica y el problema de la "invención del otro"”, en Edgardo Lander (comp.), La colonialidad del saber: eurocentrismo y ciencias sociales, Buenos Aires, CLACSO, pp. 145-162.

DArdot, Pierre y Christian Laval (2019), "La institución de lo común: ¿un principio revolucionario para el siglo XXI? Entrevista a Pierre Dardot y Christian Laval", Revista de Estudios Sociales, núm. 70, pp. 65-77. DOI: https:// doi.org/10.7440/res70.2019.06
De Lissovoy, Noah, Alexander K. Means y Kenneth Saltman (2015), Toward a New Common School Movement, Boulder, Paradigm Publisher.

Diker, Gabriela (2008), “CCómo se establece qué es lo común?”, en Graciela Frigerio y Gabriela Diker (comps.), Educar: posiciones acerca de lo común, Buenos Aires, Editorial del Estante, pp. $147-170$.

Esposito, Roberto (2009), Inmunistas. Protección y negación de la vida, Buenos Aires, Amorrortu.

Federici, Silvia (2010), Calibán y la bruja. Mujeres, cuerpos y acumulación originaria, Madrid, Traficantes de sueños.

Fernández González, Noelia (2016), “Repensando las políticas de privatización en educación: el cercamiento de la escuela", Archivos Analiticos de Políticas Educativas, vol. 24, núm. 1. DOI: https://doi.org/10.14507/epaa.24.2509

Fernández González, Noelia (2019), El cercamiento neoliberal de la escuela pública en Madrid: un estudio del discurso y la gubernamentalidad, Tesis de Doctorado, Madrid, Universidad Autónoma de Madrid.

Fernández González, Noelia (2020), “Una sociología discursiva de la política educativa: rastreando las tensiones del gobierno neoliberal de la escuela pública", Revista de Estudios Teóricos y Epistemológicos en Política Educativa, vol. 5, pp. 1-19. DOI: https://doi.org/10.5212/ retepe.v.5.15039.012

Fernández González, Noelia y Héctor Monarca (2018), "Política educativa y discursos de calidad: usos y resignificaciones en el caso español", en Héctor Monarca (coord.), Calidad de la educación en Iberoamérica: discursos, políticas y prácticas, Madrid, Dykinson, pp. 12-44. Foucault, Michael (1999), "La 'gubernamentalidad”, en Ángel Gabilondo (ed.), Estética, ética y hermenéutica, Barcelona, Paidós, pp. 175-198. 
Foucault, Michael (2007), El nacimiento de la biopolítica. Curso de Collège de France (1978-1979), Buenos Aires, Fondo de Cultura Económica.

Fraser, Nancy (2014), “Tras la morada oculta de Marx", New Left Review, núm. 86, pp. 57-76.

Fraser, Nancy y Rahel Jaeggi (2019), Capitalismo. Una conversación desde la teoría crítica, Madrid, Morata.

Frigerio, Gabriela y Graciela Diker (comps.) (2008), Educar: posiciones acerca de lo común, Buenos Aires, Editorial del Estante.

Garcés, Marina (2013), Vida en común, Barcelona, Ediciones Bellaterra.

Green, Andy (2013), Education and State Formation: Europe, East Asia and USA, Nueva York, Macmillan.

Grinberg, Silvia (2014), Educación y poder en el siglo XXI: gubernamentalidad y pedagogía en las sociedades de gerenciamiento, Buenos Aires, Miño y Dávila.

Harvey, David (2004), El nuevo imperialismo: acumulación por desposesión, Madrid, Akal.

Harvey, David (2011), "The Future of Commons", Radical History Review, núm. 109, pp. 101-107. DOI: https://doi.org/10.1215/01636545-2010-017

Hernández, Ivette (2017), Space and Politics in the Penguins'Movement: Geographies of the political construction of the Chilean student movement, Tesis de Doctorado, Londres, UCLInstitute of Education.

Hess, Charlotte y Elinor Ostrom (eds.) (2016), Los bienes comunes del conocimiento, Madrid, Traficantes de sueños.

Jessop, Bob (2009), El futuro del Estado capitalista, Madrid, Catarata.

LaClau, Ernesto y Chantal Mouffe (2001), Hegemonía y estrategia socialista, Madrid, Siglo XXI.

LANDER, Edgardo (2000), "Ciencias sociales: saberes coloniales y eurocéntricos”, en Edgardo Lander (comp.), La colonialidad del saber: eurocentrismo y ciencias sociales, Buenos Aires, CLACSO, pp. 11-40.

Laval, Christian y Pierre Dardot (2013), La razón neoliberal del mundo. Ensayo sobre la sociedad neoliberal, Barcelona, Gedisa.

Laval, Christian y Pierre Dardot (2015), Común. Ensayo sobre la revolución en el siglo XXI, Barcelona, Gedisa.

Lerena, Carlos (1984), Reprimir y liberar, Madrid, Akal.

Linebaugh, Peter (2013), El manifiesto de la Carta Magna. Comunes y libertades para el pueblo, Madrid, Traficantes de sueños.

Luxemburgo, Rosa (1967), La acumulación del capital, México, Grijalbo.

Martín Rojo, Luisa y Alfonso del Percio (2020), "Neoliberalism, Language and Governmentality", en Luisa Martín Rojo y Alfonso del Percio (eds), Language and Governmentality, Oxon, Routledge, pp. 1-26.
Martínez-Rodríguez, Francisco (2018), “'Making a Stand' against Neoliberalism: Connections between critical pedagogy and the 'Green Tides' movements for state education in Spain”, Critical Studies. Critical Methodology, vol. 19, núm. 5, pp. 360-372. DOI: https:// doi.org/10.1177/1532708618809119

Marx, Karl (1975), El capital. Libro primero. Volumen 3. El proceso de acumulación del capital, Madrid, Siglo XXI.

Means, Alexander, Derek Ford y Graham Slater (2017), Educational Commons in Theory and Practice, Nueva York, Palgrave Macmillan.

Mies, Maria (2019), Patriarcado y acumulación a escala mundial, Madrid, Traficantes de sueños.

MIRCO (2020, 7 de mayo), "La disciplina social y el cuidado de lo común: 'Solo el pueblo salva al pueblo"', ctxt. Contexto y Acción, en: https:// ctxt.es/es/20200501/Firmas/32164/MIRCOcoronavirus-disciplina-social-cuidadosriesgos-incertidumbres.htm (consulta: 7 de junio de 2021).

Mouffe, Chantal (2016), La paradoja democrática, Barcelona, Gedisa.

Negri, Antonio (2015), El poder constituyente, Madrid, Traficantes de sueños.

Newland, Carlos (1991), "La educación elemental en la Hispanoamérica: desde la independencia hasta la centralización de los sistemas educativos nacionales", Hispanic American Historical Review, vol. 71, núm. 2, pp. 335-364.

Ossenbach, Gabriela (1993), "Estado y educación en América Latina a partir de su independencia (siglos XIX y XX)", Revista Iberoamericana de Educación, núm. 1, enero-abril. DOI: https:// doi.org/10.35362/rie101243

Pineau, Pablo (2001), “¿Por qué triunfó la escuela?, o la modernidad dijo: 'Esto es educación' y la escuela respondió: 'Yo me ocupo"', en $\mathrm{Pa}$ blo Pineau, Inés Dussel y Marcelo Caruso, La escuela como máquina de educar, Buenos Aires, Paidós, pp. 27-52.

PolAnYi, Karl (2016), La gran transformación. Crítica del liberalismo económico, Barcelona, Virus.

Popkewitz, Thomas (2009), El cosmopolitismo y la era de la reforma escolar, Madrid, Morata.

Puelles Benítez, Manuel (2003), "El pacto escolar constituyente: génesis, significación y situación actual", Historia de la Educación. Revista Interuniversitaria, núm. 21, pp. 49-66.

Puiggrós, Adriana (2016), La educación popular en América Latina. Orígenes, polémicas y perspectivas, Buenos Aires, Colihue.

Querrien, Anne (1994), Trabajos elementales sobre la escuela primaria, Madrid, La Piqueta.

Ramírez, René (2014), La virtud de los comunes. De los paraísos fiscales al paraíso de los conocimientos abiertos, Quito, Abya-Yala. 
Ramírez, Francisco y John Ventresca (1992), "Institucionalización de la escolarización masiva: isomorfismo ideológico y organizativo en el mundo moderno", Revista de Educación, núm. 298, 121-139.

Rancière, Jacques (2012), El desacuerdo, Buenos Aires, Nueva Visión.

Rizvi, Fazal y Bob Lingard (2013), Políticas educativas en un mundo globalizado, Madrid, Morata.

Robertson, Susan, Xavier Bonal y Roger Dale (2002), "El AGCS y la industria de los servicios educativos", en Xavier Bonal, Aina Tarabini y Antoni Verger (eds.), Globalización y educación. Textos fundamentales, Buenos Aires, Miño y Dávila, pp. 205-232.

Rodríguez, Carmen (2014), "La proletarización del profesorado en la LOMCE y en las nuevas políticas educativas: de actores a culpables", Revista Interuniversitaria de Formación del Profesorado, vol. 81, núm. 28.3, pp. 73-87.

Rousseau, Jean-Jacques (1972), Discurso sobre el origen de la desigualdad entre los hombres, Madrid, Miguel Castellote.

Rowe, Emma (2017), Middle-class School Choice in Urban Spaces, Londres, Routledge.

SAFORCADA, Fernanda (2009), "Las políticas educativas y la nueva ofensiva privatizadora en América Latina”, en Pablo Gentili, Gudêncio Frigotto, Roberto Leher y Florencia Stubrin (comps.), Políticas de privatización, espacio público y educación en América Latina, Buenos Aires, CLACSO/Homo Sapiens, pp. 363-399.

SAIDEL, Matías Leandro (2019), "Reinvenciones de lo común: hacia una revisión de algunos debates recientes", Revista de Estudios Sociales, núm. 70, pp. 10-24. DOI: https://doi. org/10.7440/res70.2019.02
Sevilla, Álvaro (2013), “Planificar los comunes? Autogestión, regulación comunal del suelo y su eclipse en la Inglaterra precapitalista”, Scripta Nova, vol. 17, núm. 442, s/p.

Slater, Graham (2014), "Constituting Common Subjects: Toward an education against enclosure", Educational Studies: A Journal of the American Educational Studies Association, vol. 50, núm. 6, pp. 537-553. DOI: https:// doi.org/10.1080/00131946.2014.965935

SNyders, Georges (1978), Escuela, clases y lucha de clases, Barcelona, Comunicar.

Tomassi, Tina (1980), Breviario del pensamiento educativo libertario, Cali, Otra vuelta de tuerca.

UNESCO (2015), Repensar la educación. ¿Hacia un bien común mundial?, París, UNESCO.

VArela, Julia y Fernando Álvarez-Uría (1991), Arqueología de la escuela, Madrid, La Piqueta.

Verger, Antoni, Clara Fontdevila y Adrián Zancajo (2016), The Privatization of Education. A Political Economy of Global Education Reform, Nueva York/Londres, Teachers College Press.

WALLERSTEIN, Inmanuel (1988), El capitalismo histórico, Madrid, Siglo XXI.

Walsh, Catherine (ed.) (2013), Pedagogías decoloniales. Prácticas insurgentes de resistir, (re)existir y (re)vivir, tomo I, Quito, Abya-Yala.

ŽıžeK, Slavoj (1998), "Multiculturalismo o la lógica cultural del capitalismo multinacional", en Fredric Jameson y Slavoj Žižek (eds.), Estudios culturales. Reflexiones sobre el multiculturalismo, Buenos Aires, Paidós.

ŽIžEK, Slavoj (2011), Primero como tragedia, después como farsa, Madrid, Akal.

Zysman, Ariel (2013), "Educación popular, instrucción pública y alternativas pedagógicas”, en Lidia Mercedes Rodríguez (dir.), Educación popular en la historia reciente de Argentina y América Latina, Buenos Aires, APPEAL, pp. 113-123. 